\title{
Numeric Simulation of Heat Transfer Phenomena in Existing and Retrofitted Casement Windows
}

\author{
Shiva Najaf Khosravi ${ }^{1}$, Ulrich Pont ${ }^{1}$, Ondřej Šikula ${ }^{2}$, Ardeshir Mahdavi ${ }^{1}$ \\ ${ }^{1}$ Department of Building Physics and Building Ecology, TU Vienna, Austria \\ ${ }^{2}$ Institute of Building Services, Brno University of Technology, Czech Republic
}

\begin{abstract}
Transparent elements of building enclosure components play a critical role in buildings' performance and integrity. Numeric simulation provides a tool to model and predict the thermal behavior of window constructions. This paper presents a two-dimensional numerical analysis of the thermal behavior of a casement window before and after implementing a vacuum glazing in the external pane. Two modelling approaches were considered, a conventional one (focusing predominantly on conductive heat transfer) and a more detailed one (involving coupled conduction and convection). The results of the study demonstrate the benefits of the aforementioned retrofit option in terms of reduced heat transfer, increase of surface temperature within the cavity during the cold season, and the reduction of surface condensation risk.
\end{abstract}

\section{Introduction}

Energy use due to building operation has a significant impact on environment (Taleb, 2015). Improved building envelope design can contribute to reducing buildings' energy consumption (Malvoni et al., 2016).

Windows have been a subject of interest for research in building industry due to their multifaceted and significant implications for indoor environmental quality and building energy use. Regarding thermal insulation of windows, designers are expected to pay special attention toward improving the pertinent properties of the frame and glazing (Curcija, 1993). Understanding windows' thermal performance requires detailed knowledge of the relevant properties of their different elements. To be considered energy-efficient, windows require, amongst other things, a low U-Value. Thus, the materials used in must have lower thermal conductivity (Finlayson et al. 1998). There are many instances of application of numeric heat transfer for analysing windows' thermal performance (Marjanovic et al., 2005; Thalfeldt et al., 2015). Likewise, multiple studies have addressed the performance of vacuum glazing (see, for example, Proskurnina et al., 2016; Cho, 2017).

Multi-objective analyses have been carried out in several studies (Malvoni et al., 2016; Baglivo et al., 2014) to optimize the thermal performance of the windows.

There are a number of studies regarding heat transfer in multi-pane windows, which have focused on free convection in the interstitial space between the glazing layers (Yin et al., 1978; Zhao et al., 1997). Arici et al.
(2012) compared numerically the thermal behaviour of windows with double, triple, and quadruple panes, suggesting that heat loss through the transparent elements can be reduced by increasing the number of panes, especially in cold climates.

Numeric heat transfer analyses in multi-pane window have mostly focused on natural convection inside the cavity between glazing (Curcija, 1993; Yin et al., 1978; Zhao and Curcija, 1997).

Implementing vacuum glazing in buildings has been an object of broad study and application in recent years, both in new and existing constructions. However, there is little experience in predicting the actual behaviour of vacuum glazing. Within the framework of a recently completed research project, it was demonstrated that conventional (double-layered) windows can be thermally retrofitted such that one or both glazing layers are substituted with a vacuum glazing element (Proskurnina et al., 2016). Conventional - standard-based - thermal bridge analyses of such windows does not model in detail the convective heat flow generated by buoyancy forces within the interstitial air space between the two layers.

In the present study, we applied numeric simulation to study the behaviour of a conventional casement window (or, in German: "Kastenfenster") before and after application of vacuum glazing to the window's external pane. Thereby, two simulation approaches were compared. The first considers only conductive heat transfer, whereas the second involves a more detailed assessment using computational fluid dynamics (CFD) coupled with numeric simulation of conductive heat transfer.

To estimate the risk of possible condensation or mould grows, the temperature distribution as well as minimum surface temperature of the indoor window surfaces was obtained from simulation. Furthermore, the dimensionless temperature factor at the internal window wing $\left(f_{R s i}\right)$ was derived based on the following Equation 1 (ISO, 2007):

$f_{R s i}=\frac{\theta_{s i}-\theta_{e}}{\theta_{i}-\theta_{e}}$

$\theta_{s i}=$ temperature at the internal surface at the point with the lowest temperature

$\theta_{i}=$ internal temperature,

$\theta_{e}=$ external temperature. 


\section{Methodology}

To address the aforementioned research objective, a conventional casement window with an interstitial space of $150 \mathrm{~mm}$ and two operable wings was used for twodimensional heat transfer analysis. Aside from the original construction, a retrofitted version using vacuum glazing was considered for two-dimensional heat transfer as well (Figure 1). Thereby, the heat strengthened low-e vacuum glass is assumed to consist of $4 \mathrm{~mm}$ glass panes, a $0.15 \mathrm{~mm}$ vacuum layer, $8 \mathrm{~mm}$ edge sealing. The outside and inside radii of stainless support pillars are $0.30 \mathrm{~mm}$ and $0.15 \mathrm{~mm}$ respectively. Support pillars were assumed to be spaced on a $40 \mathrm{~mm}$ grid (see, Proskurnina et al., 2016, for additional explanation).

Table 1 summarizes the thermal conductivity of the constitutive elements of this construction (Synergy, 2016; Proskurnina et al., 2016). The conductivity assumption of vacuum glazing is based on the set up of the SYNERGY glass (Synergy, 2016).

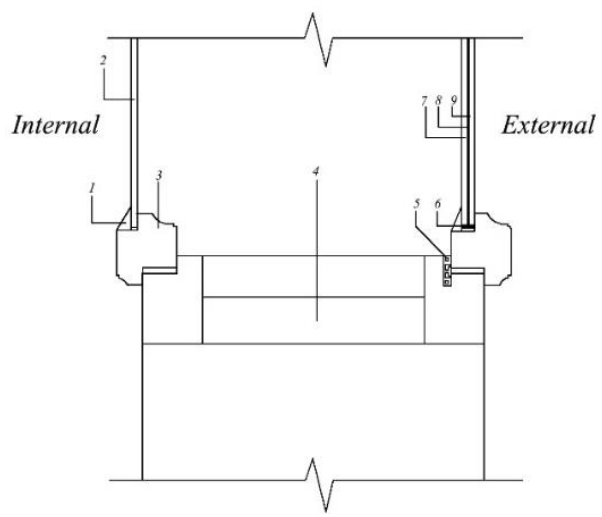

Figure 1: Casement window (retrofitted with vacuum glazing in the external wing).

Table 1: Thermal conductivity assumptions (in W. $m^{-1} \cdot K^{-1}$ ) of the constitutive elements of the selected casement window (see Figure 1).

\begin{tabular}{cc}
\hline Window construction element & $\begin{array}{l}\text { Thermal conductivity } \\
{\left[\mathbf{W} \cdot \mathbf{m}^{-\mathbf{1}} \cdot \boldsymbol{K}^{\mathbf{- 1}}\right]}\end{array}$ \\
\hline 1. Window putty & 0.375 \\
\hline 2. Lime glass & 1 \\
\hline 3. Wooden frame & 0.11 \\
\hline 4. Mineral insulation & 0.045 \\
\hline 5. Window seal & 0.3 \\
\hline 6. Silicon & 0.24 \\
\hline 7. Glass & 1 \\
\hline 8. Vacuum layer & 0.00000975 \\
\hline 9. Edge seal & 1 \\
\hline
\end{tabular}

Figure 2 illustrates the computational domain (boundary conditions and the 2D hybrid includes structured and unstructured grid. To study the temperature and velocity fields in the casement window, the reference winter temperature of the internal environment was assumed as $20^{\circ} \mathrm{C}$ and for the external environment $-10^{\circ} \mathrm{C}$. boundary conditions were assumed to be convection heat transfer on two sides and zero heat flux at the bottom and top. special care needs to be taken regarding assumptions pertaining to the convective heat transfer coefficient (Defraeye et al. 2010; Palyvos, 2008; Clear et al. 2003; Mirsadeghi et al. 2013). In this study, we used the calculation procedure described in EN ISO 10077-1(ISO 10077, 2017a). The internal and external heat transfer coefficient values were assumed to be 7.7 and $25 \mathrm{~W} \cdot \mathrm{m}^{-2} \cdot \mathrm{K}^{-1}$ respectively.

Due to the rather detailed geometric representation the targeted combined airflow and heat transfer modelling, a very fine grid had to be formed. The total number of grid element was 34453.

The thermal performance of the casement window was investigated using Computational Fluid Dynamic (CFD) ANSYS FLUENT Release 19.1. Thereby, the following steps were taken:

1. Geometry model generation

2. Definition of boundary conditions (indoor and outdoor temperatures) and material properties.

3. Numeric simulation using ANSYS FLUENT Release 19.1.

4. Post-processing of simulation results.

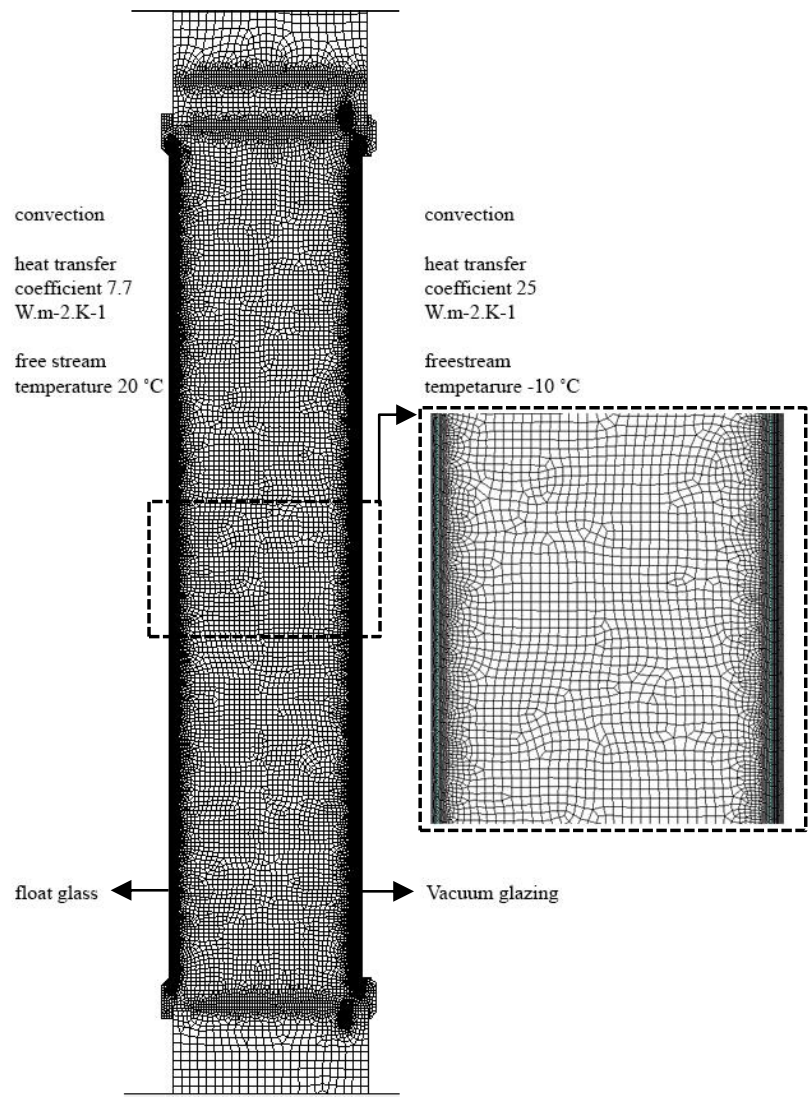

Figure 2: Boundary condition and computational grid.

The deployed CFD code uses a control-volume method to solve the coupled heat and fluid flow equations (Gustavsen et al., 2005). The computational approach (Menter, 1994) involved two-dimensional, steady-state, double precision calculation with temperature dependent thermos-physical properties for the fluid (air), constant properties for solid materials, incompressible ideal gas 
model for the buoyancy forces, the SIMPLE (SemiImplicit Model for Pressure-Linked Equations) pressure based solver, the Pressure Staggering Option (PRESTO) scheme (to find the pressure values at the cell faces), the Quadratic Upstream Interpolation for Convective Kinetics (QUICK) scheme for the momentum. Shear Stress Transitional (SST) $k-\omega$ turbulence model is suggested to simulate turbulent natural convection in a differentially heated 2D cavity (Menter, 1994, Omri and Galanis, 2007)

\section{Results and discussion}

\section{Thermal behavior of the casement window}

As mentioned before, we studied the thermal behavior of a casement window before and after implementing a vacuum glazing in the external pane. Figure 3 shows the temperature distribution in the two casement window versions for an indoor-outdoor temperature difference of $30 \mathrm{k}$. Figure 4 illustrates the air flow velocity distribution for two the simulated scenarios (original construction versus external wing retrofit).

Table 2 provides numeric information regarding the cavity mean temperature and air flow velocity for the above scenarios.

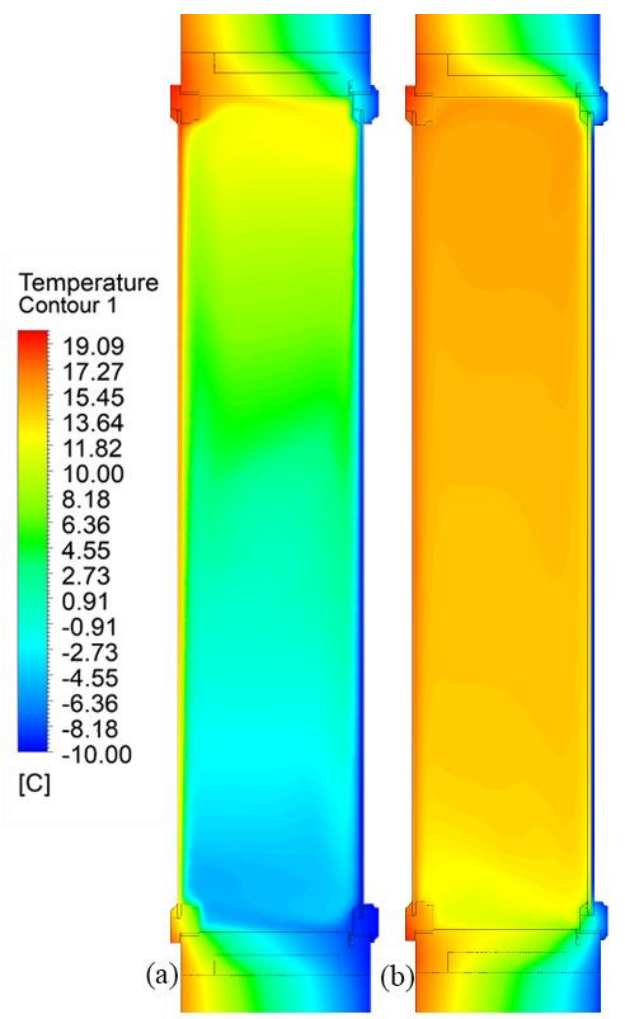

Figure 3. Temperature distribution in the casement window (a) original construction (b) retrofitted external wing.

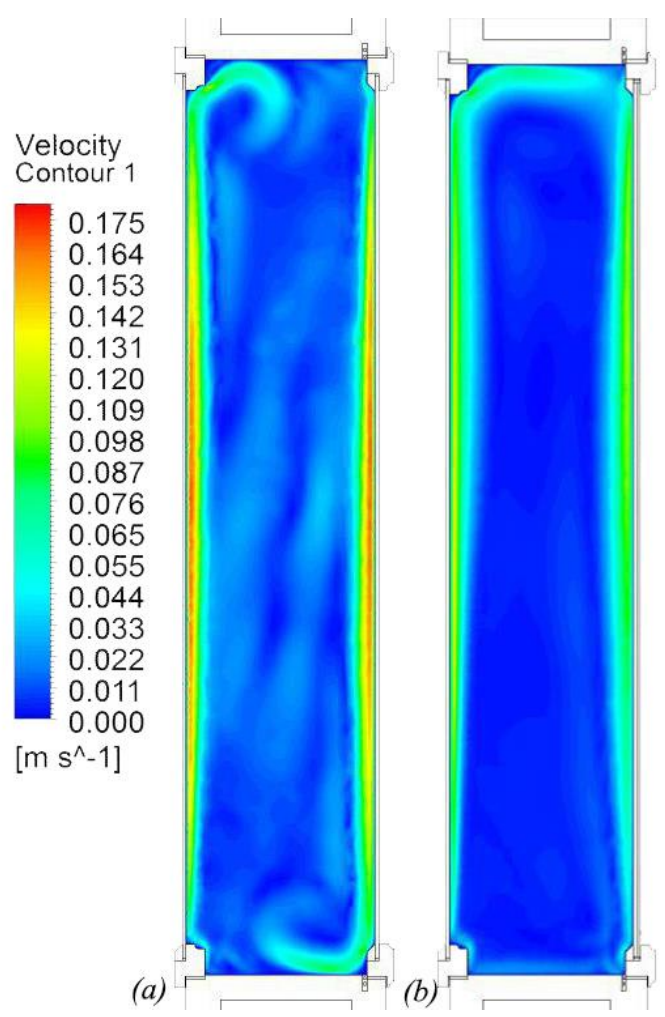

Figure 4. Distribution of velocity magnitude (a) original construction (b) external wing retrofitted.

Table2: Mean air flow velocity and temperature in the interstitial space between two wings.

\begin{tabular}{ccc}
\hline Scenario & $\begin{array}{c}\text { Mean temperature } \\
{\left[{ }^{\circ} \mathrm{C}\right]}\end{array}$ & $\begin{array}{c}\text { Mean Velocity } \\
{\left[\mathbf{m} . \mathbf{s}^{-1}\right]}\end{array}$ \\
\hline $\begin{array}{c}\text { Conventional } \\
\text { window }\end{array}$ & 2.77 & 0.057 \\
\hline $\begin{array}{c}\text { Retrofitted window } \\
\text { (external wing) }\end{array}$ & 12.16 & 0.030 \\
\hline
\end{tabular}

As expected, the upper portion of the cavity has a higher temperature (in both construction options). However, the retrofitted option generally displays, in comparison, higher temperatures and lower velocities. The velocity couture points to the influence of temperature distribution on airflow behavior. The temperature counturs in Figure 3 show higher temperature at the upper parts of the casement window.

The temperature distribution on the surface of the inner glass layer (before and after the application of vacuum glazing as a retrofit option) points to the impact of the application of vacuum glazing at the external wing (Figure 5). Respective numeric results for selected points (see Figure 5) are summarized in Table 3.

The results suggest that retrofitting the casement window via application of vacuum glazing to the external wing increases the mean cavity temperature and inner glass surface temperature. Moreover, such a retrofit reduces the mean air flow velocity in the cavity as well as the overall heat loss rate through the construction. 


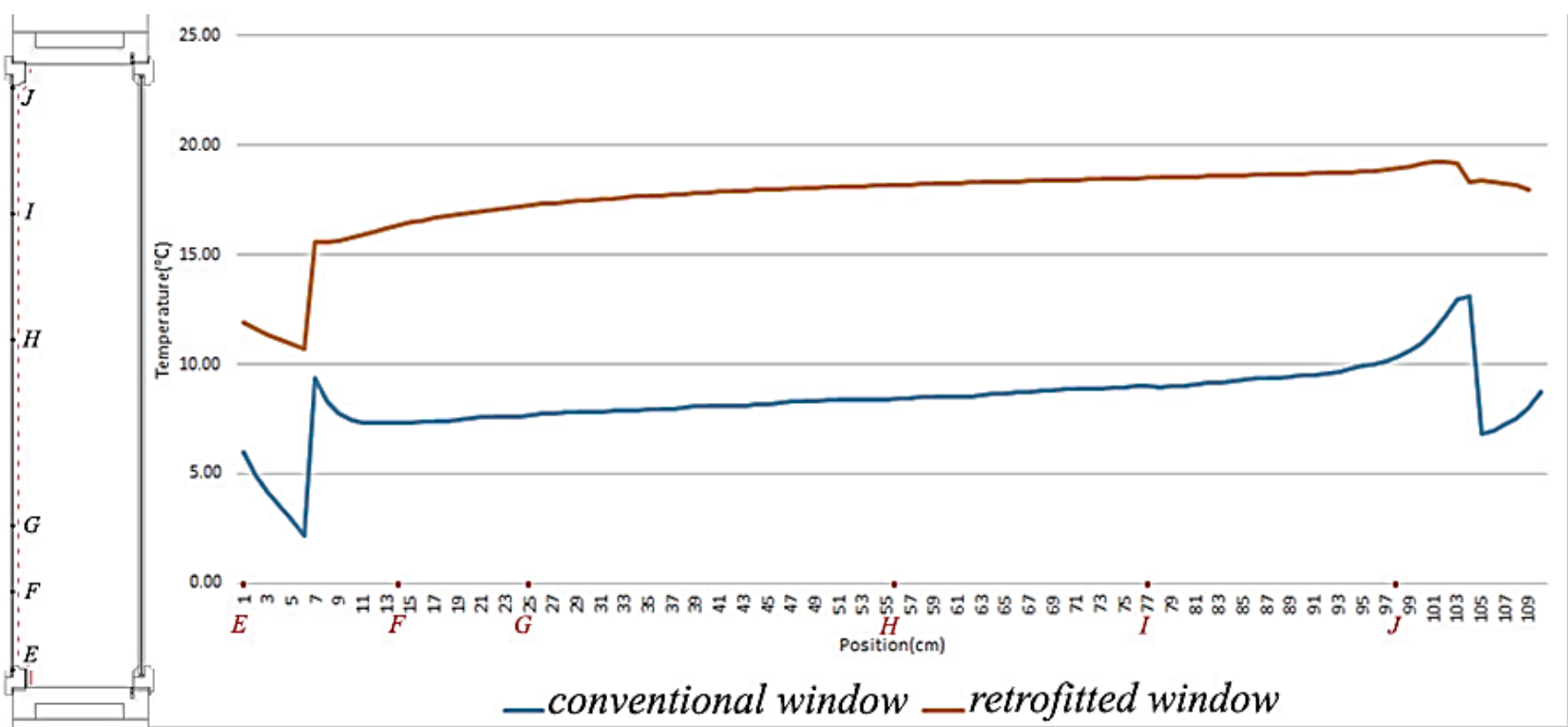

Figure 5: Temperature profile across the cavity-side surface of the inner glass layer.

Table 3: Computed surface temperatures $\left[{ }^{\circ} \mathrm{C}\right]$ at selected locations (see Figure 7) on the surface of the inner glass of the inner wing of the casement window for two scenarios.

\begin{tabular}{lcc}
\hline Points & Retrofitted window & $\begin{array}{c}\text { Conventional } \\
\text { window }\end{array}$ \\
\hline $\mathbf{E}$ & 10.71 & 2.32 \\
\hline $\mathbf{F}$ & 16.87 & 7.61 \\
\hline $\mathbf{G}$ & 17.50 & 7.96 \\
\hline $\mathbf{H}$ & 18.26 & 8.69 \\
\hline $\mathbf{I}$ & 18.57 & 9.23 \\
\hline J & 19.22 & 12.34 \\
\hline
\end{tabular}

\section{Different modelling approaches}

As discussed earlier, heat transfer processes in casement windows are highly complex, as they involve combined conduction, convection, and radiation. Thereby, amongst other things, fluid flow must be considered in order to quantify the convection effect (Gustavsen et al., 2008).

One of the goals of the present treatment was to reliably model the natural convection effects inside two panes of the casement window.

Table 4 summarizes the computed temperature of selected locations at the boundary of interstitial space and the solid element as well as minimum inside surface temperature and temperature factor for conductive only as well as coupled conductive and convective heat transfer. The location of the points is illustrated in Figure 6. Moreover, Figures 7 and 8 Show the temperature distribution across the section of the window.

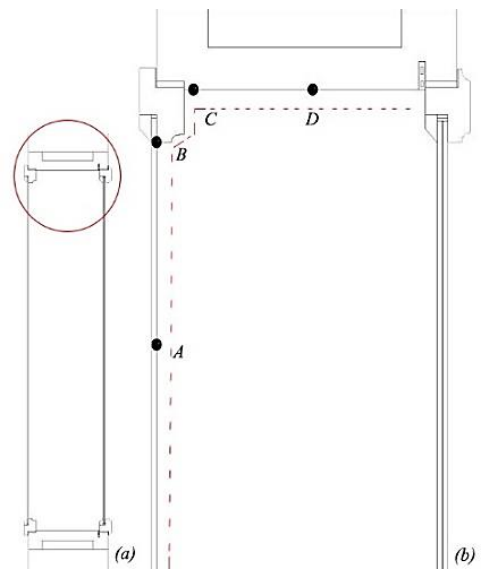

Figure 6. Illustration of the retrofitted window (a) location of selected points (b).

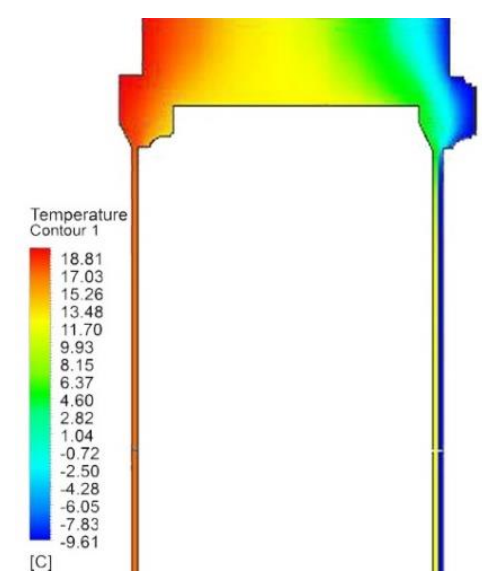

Figure 7. Temperature distribution in the section of casement window (conductive heat transfer). 


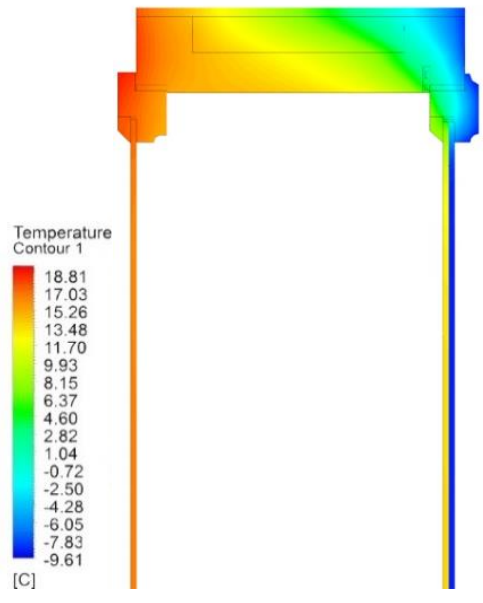

Figure 8. Temperature distribution in the section of casement window (conductive and convection heat transfer).

Table4: Temperature at the selected locations (see Figure2), minimum inside surface temperature and temperature factor (retrofitted window).

\begin{tabular}{ccc}
\hline & $\begin{array}{c}\text { Conduction based } \\
\text { model }\end{array}$ & $\begin{array}{c}\text { Convection + } \\
\text { conduction }\end{array}$ \\
\hline $\boldsymbol{A}$ & 16.93 & 18.78 \\
\hline $\boldsymbol{B}$ & 17.00 & 19.20 \\
\hline $\boldsymbol{C}$ & 14.79 & 17.38 \\
\hline $\boldsymbol{D}$ & 12.75 & 13.68 \\
\hline $\begin{array}{c}\text { Minimum inside } \\
\text { temperature }\left[{ }^{\circ} \mathrm{C}\right]\end{array}$ & 16.61 & 16.91 \\
\hline $\begin{array}{c}\text { Temperature } \\
\text { factor }\left(\boldsymbol{f}_{\text {Rsi }}\right)\end{array}$ & 0.89 & 0.90 \\
\hline
\end{tabular}

Simulation results (computed temperatures at selected points) suggest that minimum internal surface temperatures as well as associated temperature factor values are higher when the convection effect is considered. The results indicate that the retrofitted casement window exceeds the minimum temperature factor value $\left(f_{R s i}=0.71\right)$ according to the applicable regulation in Austria (OENORM B8110-2 2003). In comparison, the temperature factor for the conventional casement window is 0.59 .

Simulation software focusing purely on conduction is limited in view of modelling air flow velocity and temperature distribution in windows' cavity spaces. Hence, coupling of conductive heat transfer code with a CFD model is necessary, if a more detailed comparison of the two casement window options (conventional versus retrofitted with vacuum glazing in the exterior window wing) is to be performed.

\section{Conclusion}

Windows are typically characterized as thermally weak points in building envelopes. Improving their thermal behaviour can reduce buildings' energy demand. The results of our numeric assessment show that the integration of vacuum glazing in the external wing of a casement window can significantly influence the temperature and air distribution inside of the construction's cavity. Moreover, such a retrofit can reduce heat loss through the window construction.

The study also highlights the difference in results due to different modelling approaches. Specifically, purely conductive simulations of the thermal behaviour of the casement window leads to results different from those obtained via coupled conductive and convective heat transfer simulation. As such, a more reliable modelling approach requires the consideration of convective processes associated with air flow within the cavity space of a casement window.

Ongoing and future studies in this context intend to address a number of limitations of the present treatment. For one thing, the present study was limited to twodimensional heat transfer analysis. Likewise, only conduction and convection processes in the casement window were considered. Hence, additional studies are to be undertaken toward three-dimensional heat transfer modeling as well as a more inclusive process modeling domain, involving conduction, convection, and radiation phenomena. Last but not least, a larger variety of construction details and climatic contexts are to be taken into consideration.

\section{Acknowledgement}

The study presented in this paper was informed by past and ongoing and research efforts pertaining to the exploration of vacuum glass as a potential technology for contemporary windows and window retrofit. These efforts have been conducted at the Department of Building Physics and Building Ecology of TU Vienna, together in collaboration with the Holzforschung Austria, and were funded by the Austrian Research Promotion Agency FFG: Project FIVA (ongoing), Project-No: 867352; Project MOTIVE (2016-2017), Project-No: 854690; Project VIG-SYS-RENO (2014-2015), ProjectNo: 845225 .

\section{References}

Arici, M., Yücel, A., \& Karabay, H. (2012). Comparison of heat transfer in vertically and horizontally installed double-pane windows. 6th International Ege Energy Symposium \& Exhibition, June 28-30, 2012, Izmir, Turkey, 28-30.

Baglivo, C., Congedo, P. M., Fazio, A. (2014). Multicriteria optimization analysis of external walls according to ITACA protocol for zero energy buildings in the Mediterranean climate. Building and Environment, 82, 467-480.

Gustavsen, A., Arasteh, D., Jelle, B.P., Curcija, C. Kohler, C. (2008). Developing Low-Conductance Window Frames: Capabilities and Limitations of Current Window Heat-Transfer Design Tools. Journal of Building Physics, 32(2), 131-153.

Cho, S. (2017). Analysis of the performance of vacuum glazing in office buildings in Korea: Simulation and experimental studies. Sustainability (Switzerland), 9(6). https://doi.org/10.3390/su9060936. 
Clear, R. D., Gartland, L., and Winkelmann, F. C. (2003). An empirical correlation for the outside convective air-film coefficient for horizontal roofs. Energy and Buildings, 35(8), 797-811. https://doi.org/10.1016/ S0378-7788(02)00240-2.

Defraeye, T., Blocken, B., \& Carmeliet, J. (2010). Convective heat transfer coefficients for exterior building surfaces: Existing correlations and CFD modelling. Energy Conversion and Management, In Press,(0), 1-20. http://www.sciencedirect.com/ science/article/B6V2P-50PJJ02-9/2/ec77e5efbfddc 3a222f1ae08fdd0174a.

EN ISO 10077-1:2017 Thermal performance of windows, doors and shutters - calculation of thermal transmittance.

Finlayson, E., Mitchell, R., Arasteh, D., Huizenga, C., \& Curcija, D. C. (1998). THERM 2.0. Program description. A PC program for analyzing the twodimensional heat transfer trough building products. University of California, Berkeley.

ISO. (2007). ISO 10211:2007 Thermal bridges in building construction - heat flows and surface temperatures.

Gustavsen, A., Arasteh, D. K., Kohler, C., \& Curcija, D. C. (2005). Two-Dimension Conduction and CFD Simulations for Heat Transfer in Horizontal Window Frame Cavities. 2005 ASHRAE Winter Meeting, 111, 1-13.

Vollaro, L., Andrea de , Giorgio G. \& Vallati, A. (2015). CFD Analysis of Convective Heat Transfer Coefficient on External Surfaces of Buildings. Sustainability, 7(7), 9088-9099.

Malvoni, M., Baglivo, C., Congedo, P. M., \& Laforgia, D. (2016). CFD modeling to evaluate the thermal performances of window frames in accordance with the ISO 10077. Energy, 111, 430-438. https://doi.org/10.1016/j.energy.2016.06.002.

Marjanovic, L., Cook M., Hanby, V., \& Rees, S. (2005). CFD Modeling of Convective Heat Transfer From a Window With Adjacent Venetian Blinds.

Menter, F. R. (1994). Two-Equation Eddy-Viscosity Turbulence Models for Engineering Applications. AIAA Journal, 32(8), 1598-1605.
Mirsadeghi, M., Cóstola, D., Blocken, B., \& Hensen, J. L. M. (2013). Review of external convective heat transfer coefficient models in building energy simulation programs: Implementation and uncertainty. Applied Thermal Engineering, 56(12), 134-151. https://doi.org/10.1016/J.APPL THERMAL ENG.2013.03.003

Proskurnina, O., Pont, U., Mahdavi, A. (2016). The Performance of Vacuum Glazing in Existing Window Constructions: a Case Study. Proceedings of the Symposium on Building Physics CESBP Central European AND BauSIM, 650-669.

OENORM B8110-2, 2003-07. (2003). Minimum Requirements for fRsi-Values in Austria.

Omri, M., and Galanis, N. (2007). Numerical analysis of turbulent buoyant flows in enclosures: Influence of grid and boundary conditions. International Journal of Thermal Sciences, 46(8), 727-738. https://doi.org/10.1016/j.ijthermalsci.2006.10.006.

Palyvos, J. A. (2008). A survey of wind convection coefficient correlations for building envelope energy systems' modeling. Applied Thermal Engineering, 28(8-9), 801-808. https://doi.org/ 10.1016/j.applthermaleng.2007.12.005.

Yin, S.H., Wung, T., Chen, K. (1978). Natural convection in an air layer enclosed within rectangular cavities. International Journal of Heat Mass Transfer, 21, 307-315.

Synergy. (2016). Beijing Synergy Vacuum Glazing Technology. Retrieved from www.bjsng.com.

Taleb, H. M. (2015). Natural ventilation as energy efficient solution for achieving low-energy houses in Dubai. Energy and Buildings, 99, 284-291. https://doi.org/10.1016/j.enbuild.2015.04.019.

Thalfeldt, M., Kurnitski, J., \& Voll, H. (2015). Comparison of simplified and detailed window models in office building energy simulations. Energy Procedia, 78, 2076-2081. https://doi.org/ 10.1016/j.egypro.2015.11.235

Zhao, Y., Goss, W.P.,Curcija, D. (1997). Prediction of the multicellular flow regime of natural convection in fenestration glazing cavities. ASHRAE Transactions, 103(1), 1009-1020. 